\title{
Fenoxycarb effect on quality, productive capacity and food safety of Kabardinskaya rannyaya cultivar of the plum
}

\author{
Marina Podgornaya ${ }^{*}$, Anfisa Vasilchenko, and Nadezhda Didenko \\ FSBSI «North Caucasian Regional Research Institute of Horticulture, Viticulture, Wine-making», 40- \\ Years of Victory Str., 39, Krasnodar, 350901, Russia
}

\begin{abstract}
Plum moth Grapholita funebrana Tr. is a dominating pest in entomological complex of plum production in the south of Russia. The yield's loss caused by it can reach 60-70\%. In the modern plant protection systems Insegar, VDG ( $250 \mathrm{~g} / \mathrm{kg}$ fenoxycarb) is most commonly used for control of the pest's number. Its use helps to save up to $98.5-99.8 \%$ of the fruit. The aim of the research was to study fenoxycarb`s effect on quality, productive capacity and food safety of Kabardinskaya rannyaya cultivar of the plum. It was found that double use of the insecticide doesn't lead to significant difference in the content of organic acids and dry substances. However, it encourages the increase of the leaf's surface by $4-10 \mathrm{sm}^{2}$ and annual additional growth of the plant by $6-52 \mathrm{sm}$ in comparison to the control. It was established that fenoxycarb is completely decomposed at the end of the "Waiting period".
\end{abstract}

\section{Introduction}

In plum agrocenoses of the south of Russia, crop loss caused by the plum codling moth Grapholita funebrana Tr. can reach $60-70 \%$. For control of the phytophage`s number in modern plant protection systems Insegar, VDG $(250 \mathrm{~g} / \mathrm{kg}$ fenoxycarb) of insecticides` class of juvenoids, is most often used. In foreign and Russian scientific literature there is some information about the product's biological effectiveness in G. funebrana Tr. control. But there is no data on the insecticide's effect on the protected plant. Therefore, the aim of the study was to study the effect of fenoxycarb on the quality, productivity and food safety of early Kabardinskaya rannyaya plum.

From scientific literature it is known that by action's mechanism fenoxycarb $\left(\mathrm{C}_{17} \mathrm{H}_{19} \mathrm{NO}_{4}\right)$ is classified as an insect growth regulator (IGR), and belongs to the carbamates ' class of insecticides and is used for control of lepidopteran pests. Unlike conventional insecticides, IGR does not cause phytophages' death. The slowdown in population growth occurs: under the juvenoids` influence on the insects 'endocrine system, leading to disruption of the normal reproductive functions. Fenoxycarb provokes a halt in embryonic development, which causes the egg`s death and does not allow to start molting and metamorphosis into an adult insect processes $[1,2,3,4,5]$. 
Insegar, VDG has a relatively low water solubility and is easily absorbed by soil. It degrades relatively quickly in soil under microbes' influence. It is resistant to photodegradation in the most fertile soil types. Studies of the foreign literature data indicate that fenoxycarb quickly decomposes into several components that do not accumulate and quickly decompose to $\mathrm{CO}_{2}[6]$.

\section{Methods of research}

The studies were conducted in 2017-2019 at the perennial site of the Federal State Budgetary Scientific Institution FSBSI «North Caucasian Regional Research Institute of Horticulture, Viticulture, Wine-making», Krasnodar, Russia. Soil and fruit samples were taken in the variant with two-times use of Insegar, VDG $(250 \mathrm{~g} / \mathrm{kg}$ fenoxycarb) insecticide at the rate of $0.4 \mathrm{~kg} / \mathrm{ha}$ and in the control version [7]. Fruit and soil samples from the test trees were taken on the day 0 ( 5 hours after treatment), 10, 20 and 30 days after the last treatment. The content of fenoxycarb residues in soil samples and plum fruits was determined by HPLC on a Knauer liquid chromatograph, with a variable-wavelength ultraviolet detector, on a chromatographic steel column $15 \mathrm{~cm}$ long, $4 \mathrm{~mm}$ inner diameter, containing Diasfer 110-C18 $(5 \mu \mathrm{m})$. For all experiments, the following parameters were used: mobile phase $-\mathrm{CH}_{3} \mathrm{CN}-0.005 \mathrm{M}$ ortho-phosphoric acid solution in relation to $65: 35$; eluent flow rate $0.8 \mathrm{~cm}^{3} / \mathrm{min}$; wavelength $230 \mathrm{~nm}$; fenoxycarb exit time 4.88 minutes. Quantification of fenoxycarb residues in the extracts was carried out using calibration curves using the ClarityChrom program. The arithmetic mean of two parallel measurements, the deviation of which did not exceed $3 \%$, was taken as the result. The results were compared with hygiene standards that make up for fenoxycarb: MPC $0.03 \mathrm{mg} / \mathrm{kg}$ and MDA - $0.01 \mathrm{mg} / \mathrm{kg}[8,9,10,11]$.

\section{Results of research}

As the studies` result the stimulating effect of IGR on early Kabardinskaya rannyaya plum varieties productivity indicators were confirmed. It was established that two-times treatment with Insegar VDG leads to the increase in the area of the leaf surface by $4-10 \mathrm{~cm}^{2}$ and the length of the annual growth by $6-52 \mathrm{~cm}$ in comparison to the control. High indicators of 2017 are due to heavy rainfall in spring-summer period, which accounts for $109-233 \%$ of the norm (Figure 1 ).

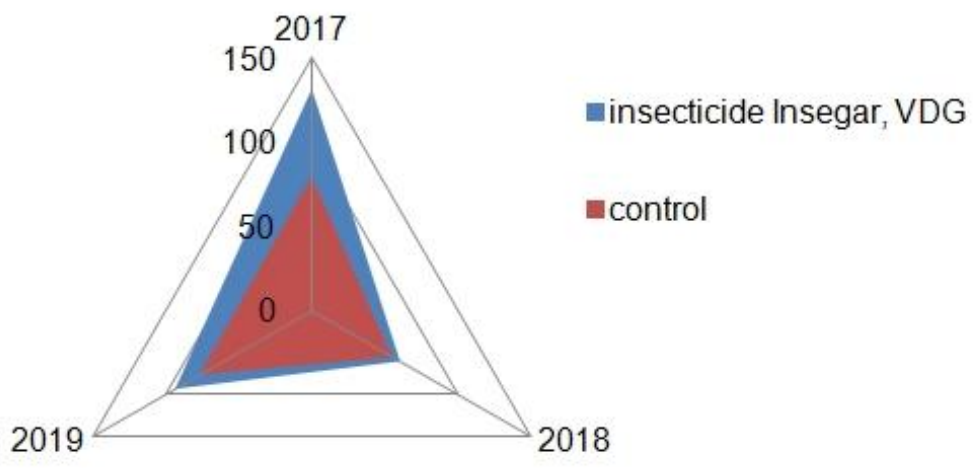

Fig. 1. The effect of the insecticide Insegar, VDG on the length of the annual growth of Kabarbinskaya rannyaya plum cultivar, $\mathrm{cm}$ 
On the average in the course of three years' research, it was found that when IGR is used, it does not lead to significant differences in the content of organic acids, dry and mineral substances in plum fruits in comparison with the control (Figure 2).

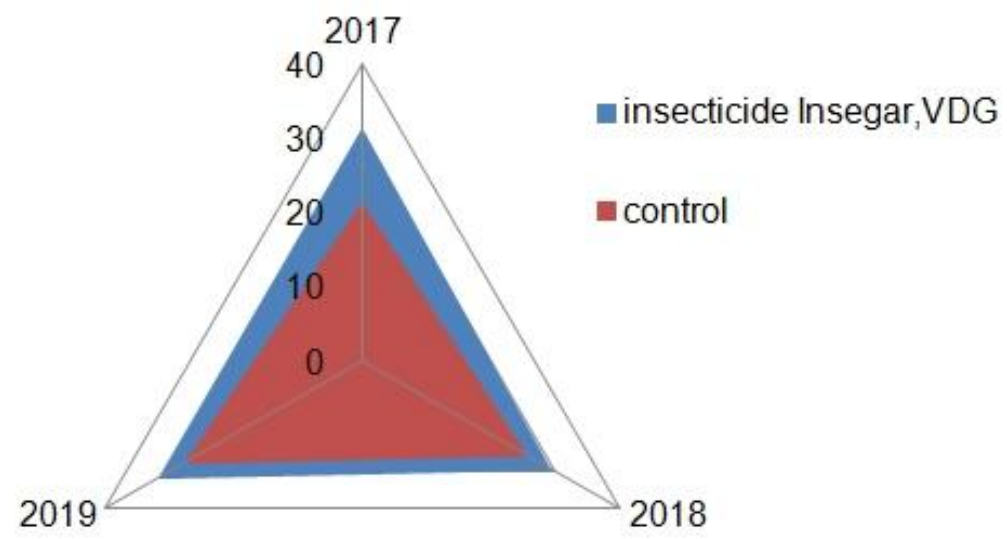

Fig. 2. The effect of the insecticide Insegar, VDG on the leaf surface area of the early Kabardinskaya rannyaya plum variety, $\mathrm{cm}^{2}$

To date, the dynamics of the decomposition of residual amounts of fenoxycarb in the plum coenosis has not been studied; foreign sources have data on the detection of xenobiotics in apples, oranges, peaches and olives [12, 13, 14, 15].

As the result of the studies conducted for the first time for plum cenoses in the South of Russia, the degradation rate of juvenoids ' class insecticide in soil - plant - product ecosystem was determined. It has been established that after two-times use of Insegar insecticide, WG at the rate of $0.4 \mathrm{~kg} / \mathrm{ha}$, fenoxycarb completely decomposes after the "waiting period" on the 30th day both in the fruits of the Kabardinskaya rannyaya plum and in soil under its plants (Figure 3).

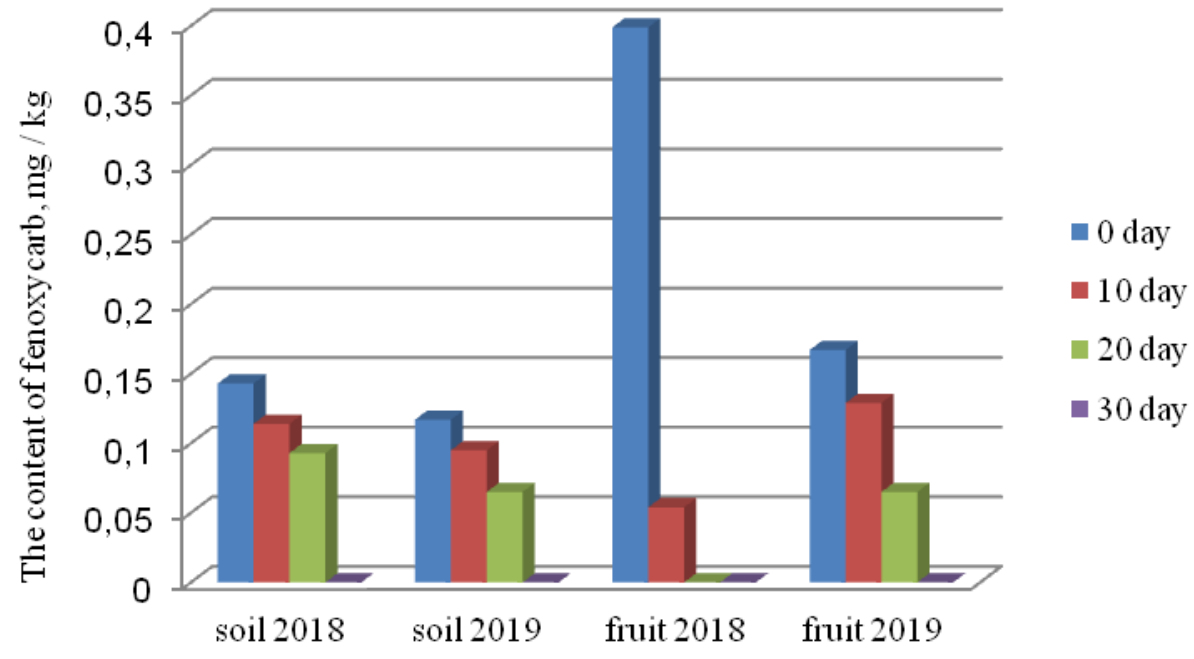

Fig. 3. The content of fenoxycarb residues in soil and plum fruits 
Thus, in plum agrocenoses of the near Kuban river's zone of the central horticulture subzone of the Krasnodar Territory, the effect of fenoxycarb on the quality, productivity and food safety of Kabardinskaya Rannyaya plum variety has been established. It was revealed that the 2-fold use of Insegar, VDG with a consumption rate of $0.4 \mathrm{~kg} / \mathrm{ha}$ does not lead to significant differences in the content of organic acids and dry substances, but it contributes to an increase in the area of the leaf blade by $4-10 \mathrm{~cm}^{2}$ and the length of the annual growth by $6-52 \mathrm{~cm}$ in comparison with the control. It was found that fenoxycarb completely decomposes in soil and plum fruits at the end of the "Waiting period".

\section{References}

1. N. Smirnov, Science Direct, Physiology of the Cladocera, 151-174, (2017), https://doi.org/10.1016/B978-0-12-805194-8.00011-8

2. T. Chen. T.-X. Liu, Florida Entomologist, 84(4), 628-633, (2001), http://dx.doi.org/10.2307/3496394

3. K. Ghoneim, R. Bakr, Egyptian Academic Journal of Biological Sciences, 11(3), 45 138, (2018), $\quad$ https://eajbsa.journals.ekb.eg/article 11687 6a4beb358408e0a734f5 aa0db11bf0dc.pdf

4. C. A. Banu, International Journal of Advanced Research, 7(6), 80-86, (2019), http://dx.doi.org/10.21474/IJAR01/9198

5. S. G. Dedos, H. Fugo, Zoological science, 18, 771-777, (2001), https://doi.org/10.2108/zsj.18.771

6. J. Sullivan, Springer, Revievs of Enironmental Contamination and Toxicologi, 202, 155 - 184, (2010), https://doi.org/10.1007/978-1-4419-1157-5_3

7. M. E. Podgornaya, G. V. Yakuba, N. A. Chill, S. R. Cherkezova, A. V. Vasilchenko, I. G. Mishchenko, Yu. P. Kashchits, Scientific works of the FSBSI «NCRRIHVW», 23, 181-188, (2019), https://elibrary.ru/download/elibrary 38191416 22389504.pdf

8. N. A. Didenko, M. E. Podgornaya, Scientific works of the FSBSI «NCRRIHVW», 26, 210-214, (2019), https://elibrary.ru/download/elibrary 41375363 39611947.pdf

9. European Commission, EUR-Lex, 32016R0486, (2016), https://eurlex.europa.eu/eli/reg/2016/486/oj

10. European Commission, Directorate-General for Health and Food Safety, EUR-Lex, 32019R0533, (2019), http://data.europa.eu/eli/reg_impl/2019/1793/oj

11. J. Zeglinski, M. Kuhs, K. R. Devi, D. Khamar, A. C. Hegarty, D. Thompson, A. C. Rasmuson, Crystal Growth \& Design, 19(4), 2037-2049, (2019), https://doi.org/10.1021/acs.cgd.8b01387

12.EFSA, 13(7), (2015), https://doi.org/10.2903/j.efsa.2015.4202

13. A. Brancato, D. Brocca, C. D. Lentdecker, Z. Erdos, L. Ferreira, L. Greco, S. Jarrah, D. Kardassi, R. Leuschner, C. Lythgo, P. Medina, I. Miron, T. Molnar, A. Nougadere, R. Pedersen, H. Reich, A. Sacchi, M. Santos, A. Stanek, J. Sturma, J. Tarazona, A. Theobald, B. Vagenende, A. Verani, L. Villamar-Bouza, EFSA, 16(1), (2018), https://doi.org/10.2903/j.efsa.2018.5155

14. O. Tiryaki, C.Temur, J. BIOL. ENVIRON. SCI., 4(10), 29-38, (2010), https://www.researchgate.net/profile/Osman_Tiryaki/publication/303720878 The fate of pesticide in the environment/links/58456f3708ae61f75dd786ec/The-fate-of-pesticide-inthe-environment.pdf

15. M. E. Poulsen, M. Wenneker, J. Withagen, H. B. Christensen. Crop Protection. 35, 5-14, (2012), https://doi.org/10.1016/j.cropro.2011.12.013 